\title{
Assessment of Knowledge, Attitude, Practice and Associated Factors Towards Post-Exposure Prophylaxis for HIVIAIDS among Health Professionals in Health Centers Found in Harari Region, Eastern Ethiopia
}

\section{Mohammed Shamil \\ Nanati Legese \\ Yohannes Tadiwos (iD)}

School of Pharmacy, College of Health and Medical Sciences, Haramaya University, Harar, Ethiopia
Correspondence: Yohannes Tadiwos School of Pharmacy, College of Health and Medical Sciences, Haramaya University, P.O. Box 235, Harar, Ethiopia Email ytadios@yahoo.com
This article was published in the following Dove Press journal: HIVIAIDS - Research and Palliative Care

Background: Healthcare workers are at risk of acquiring human immunodeficiency virus (HIV) infections, because of occupational exposure to blood and other body fluids. Post-exposure prophylaxis (PEP) is a short-term antiretroviral treatment used to reduce the likelihood of viral infection after exposure to the blood or body fluids of an infected person. Timely PEP after exposure to high-risk body fluids in the working area can reduce the rate of transmission of HIV significantly. Objective: To assess the knowledge, attitude, practice, and associated factors towards PEP for HIV/AIDS among health professionals in health centers in the Harari region, Eastern Ethiopia.

Methodology: A retrospective cross-sectional study was conducted using structured questionnaires from March to April 2019. The collected data were analyzed by using SPSS version 20, and the result was presented in the form of tables and figures.

Results: Of 217 participants, $51.6 \%$ were male and $75.2 \%$ were in the age group of $20-30$ years. One hundred thirty $(59.9 \%)$ respondents had a year of service less than 5 years, and nearly half (45.2\%) of the participants had a Diploma. The study revealed that $35.02 \%$ of the participants had inadequate knowledge of PEP. About $32.26 \%$ had an unfavorable attitude towards PEP. Of 124 (57.1\%) exposed respondents, 54 (68.4\%) tried to get PEP service and $49(90.7 \%)$ started to use PEP. Twenty-six (48.1\%) respondents started to use PEP within 6 to 24 hours after exposure. Sex, qualification, and attitude status were found to have a significant association with knowledge regarding PEP.

Conclusion: The findings of this study indicated that a significant number of health professionals had poor knowledge and poor attitude towards PEP. Occupational exposures were common among health professionals. However, the practice of using PEP was low among health professionals. As a result, health facilities should strengthen and integrate routine PEP services by providing training to all health professionals.

Keywords: knowledge, attitude, practice, post-exposure prophylaxis, HIV/AIDS, health professionals, Harari region

\section{Background}

The major mode of transmission for Human Immunodeficiency Virus (HIV) is sexual contact, but the various modes of transmission may be classified as occupational (work setting at health care) and non-occupational. Occupational or workplace exposure is 
when someone who works in a healthcare setting is potentially exposed to material infected with HIV. $^{1}$ Healthcare workers (HCW) can be exposed to HIV by needle stick injuries or cut blood or fluid splash to their eye, mouth, and injured skin. The risk for occupational transmission varies with the type, severity of the exposure, stage of disease of source patient, length of time of contact, the potential port of entry, and presence of more virulent strains of the virus. Research findings revealed that the estimated risk for HIV transmission after injury through a needle contaminated with HIV/Acquired Immune Deficiency Syndrome (AIDS) infected blood and after mucous membrane, exposure is $0.3 \%$ and $0.1 \%$, respectively. ${ }^{2}$

Post-exposure prophylaxis (PEP), is a short-term antiretroviral (ARV) treatment applied to reduce the likelihood of HIV infection after potential exposure to HIV either occupationally or non-occupationally. Within the health sector, PEP should be provided as a compressive universal precaution package; that reduces staff exposure to infectious hazards at the workplace. ${ }^{2}$

The US guidelines outline several requirements in determining whether the HCW should receive PEP and in choosing the type of PEP regimen. For most HIV exposures, for which PEP is given, a basic 4 weeks and two drug regimen is recommended. For HIV exposures that put an increased risk of transmission, a three-drug regimen may be recommended. ${ }^{3}$

The efficacy of PEP is related to the specific regimen, timing of PEP, and exposed workers' adherence to the PEP regimen. To be effective, it should be initiated within 72 hours of exposure, but more likely effective if initiated within 1 to 2 hours and not considered beyond 72 hours. However, it is not $100 \%$ effective and does not guarantee someone exposed to HIV will not become infected with HIV. ${ }^{4,5}$ The uses of PEP after exposure depend on the knowledge and attitude of HCWs about it. ${ }^{5}$

However, a study regarding knowledge, attitude, and practice (KAP) about PEP was lacking in health professionals working in health centers (HCs) at Harar region, the Eastern part of Ethiopia. This would help in reducing the risk of infection for the health professionals while rendering service to the patients and help to plan and implement interventions to reduce the chance of infection and better utilization of PEP. Thus, this study was aimed at assessing the KAP of health professionals about PEP against HIV/AIDS in HCs to fill the gap on the KAP of healthcare professionals for HIV/ADIS prevention and treatment.

\section{Methods}

\section{Study Setting}

This study was conducted in Harari regional state, eastern Ethiopia. There are four governmental hospitals and eight health centers from which, 4 of them are found in Harar town and the rest in the rural part of the town. This study was conducted on health professionals of the health centers in the Harari region, from March 15 to April 1, 2019.

\section{Study Design and Period}

A cross-sectional study design was employed to assess the KAP of health professionals about PEP against HIV infection in the eight health centers of the Harari region, Eastern Ethiopia.

\section{Sample Size Determination and Sampling Technique}

The sample size was calculated using the single population proportion formula, with $50 \%$ prevalence, $5 \%$ marginal error, 95\% confidence interval and since the exact number of source population was less than 10,000 , correction formula was used and a sample of 197 was reached. After adding a $15 \%$ non-response rate, a final sample of 227 was found. The total number of health professionals in the health centers was 402 . The sample size was then allocated proportionally to the eight health centers based on the number of health professionals in each health center (Figure (Supplementary)). Finally, participants who met the inclusion criteria were selected from the HCs using simple random sampling by using the lottery method.

\section{Data Collection Tools and Procedures}

A self-administered questionnaire was used to collect information on the KAP of healthcare professionals towards PEP. The data collection tool was adapted after reviewing different literature, guidelines, and previous studies, which were organized according to the objectives of the study. The data collection tools contain four different parts which include socio-demographic characteristics; existing knowledge about PEP, attitude, and practice towards PEP. The prepared questionnaire was pre-tested on $5 \%$ of the respondents. Before starting data collection, a brief explanation was given by the principal investigator on how to fill the questionnaire to avoid any ambiguity and misconception. 


\section{Data Processing and Analysis}

The collected data was checked at the end of each data collection day for completeness and consistency and data analysis was done by using statistical package for social science (SPSS) version 20 software. Logistic regression was done to determine any association and a P-value of $<0.05$ was considered statistically significant. Finally, obtained results were presented using tables and charts.

\section{Operational Definitions}

Risk of exposure while at work - Exposure of HCW to blood, patient body fluids or needle prick injury or sharp injury at the workplace

HIV PEP: An anti-retroviral therapy, given in different forms after occupational exposure (OE) to HIV and will be given to HCWs if there is a percutaneous injury (for example, needle-stick or cut with a sharp object), contact with a mucous membrane or non-intact skin (for example, skin chapped or abraded or dermatitis) or prolonged contact with skin or contact that involves an extensive area of skin. $^{2}$

Good knowledge: When the respondent correctly answers $\geq 75 \%$ of knowledge questions. ${ }^{6}$

Moderate knowledge: When the respondent correctly answers $50 \%$ to $74 \%$ of knowledge questions. ${ }^{6}$

Poor knowledge: When respondents correctly answer $<50 \%$ of knowledge questions. ${ }^{6}$

Good attitude: When the respondents correctly answer $>70 \%$ of attitude questions. ${ }^{7}$

Poor attitudes: When respondents correctly answer $<70 \%$ of attitudes questions. ${ }^{7}$

Regimen: A course of treatment, possibly combination drugs, exercises; diets, etc. designed to bring about an important improvement in health. ${ }^{8}$

Universal precautions: Universally adopted measures taken before the medical procedure to avoid the risk of exposures while on work. ${ }^{8}$

\section{Results}

\section{Socio-Demographic Characteristics of the Study Sample}

Out of 227 participants, 217 took part in this study, with a response rate of $95.6 \%$. More than half of the respondents $112(51.6 \%)$ were male. Ninety-six $(44.2 \%)$ were in the age range of 26-30 years. The majority of the
Table I Socio-Demographic Characteristics of Healthcare Professionals, in Health Centers of Harari Region, Eastern Ethiopia, March-April 2019

\begin{tabular}{|l|l|l|l|}
\hline Variables & Category & Number & Percent \\
\hline Age & $20-25$ & 85 & 39.2 \\
& $26-30$ & 96 & 44.2 \\
& $30-35$ & 17 & 7.8 \\
& $36-40$ & 7 & 3.2 \\
& $>40$ & 12 & 5.5 \\
\hline Sex & Male & 112 & 51.6 \\
& Female & 105 & 48.4 \\
\hline \multirow{2}{*}{ Profession } & Physician & 12 & 5.6 \\
& Nurse & 77 & 35.5 \\
& Lab technician & 35 & 16.1 \\
& Public health & 31 & 14.3 \\
& Midwife & 37 & 17.1 \\
& Others & 25 & 11.5 \\
\hline Year of service & $0-5$ & 124 & 57.1 \\
& 6-10 & 61 & 28.1 \\
& II-15 & 20 & 9.2 \\
& $>15$ & 12 & 5.5 \\
\hline Level of qualification & First Degree & 92 & 42.4 \\
& Master Degree & 11 & 5.1 \\
& General Practitioner & 12 & 5.5 \\
& Diploma & 98 & 45.2 \\
& Others & 4 & 1.8 \\
\hline \multirow{5}{*}{ Monthly income } & $1000-2000$ & 5 & 2.3 \\
& $200 I-4000$ & 124 & 57.1 \\
& $400 I-6000$ & 51 & 23.5 \\
& $>6000$ & 37 & 17.1 \\
\hline
\end{tabular}

respondents $77(35.5 \%)$ were nurses and 124 (57.1\%) had a year of service of fewer than 5 years (Table 1).

\section{Knowledge About Occupational Exposure and Universal Precaution}

Most of the participants, 209 (96.3\%) had information about the risk of OE. Exposures by sharp cut 171 (78.8\%) and needle stick injury 167 (76.9\%) were considered by the majority. Most of the respondents 207 (95.3\%) have heard about universal precaution (UP) and $201(92.6 \%)$ knew at least one type of UP. Of these, 190 (87.5\%) considered hand washing before and after any procedure as one way of UP. When asked about the different measures to be taken by the health professional immediately after OE, 89 (41.0\%) of the health professionals consider washing the exposed area with soap and water whereas 46 (21.2\%) consider washing with alcohol and iodine (Table 2). 
Table 2 Knowledge About Occupational Exposure, and Universal Precaution and Measures to Be Taken Among Health Professionals in $\mathrm{HC}$ in the Harari Region, Eastern Ethiopia, March-April, 2019

\begin{tabular}{|c|c|c|c|}
\hline Variables & Category & $\begin{array}{l}\text { Frequency } \\
\text { Yes }\end{array}$ & Percent \\
\hline Knowledge about $\mathrm{OE}^{*}$ & $\begin{array}{l}\text { Heard about the risk of occupational exposure } \\
\text { What types of exposure? } \\
\text { Sharp cut } \\
\text { Needlestick injury } \\
\text { Mucosal contact } \\
\text { Skin cut }\end{array}$ & $\begin{array}{l}209 \\
171 \\
167 \\
146 \\
121\end{array}$ & $\begin{array}{l}96.3 \\
78.8 \\
76.9 \\
67.2 \\
55.7\end{array}$ \\
\hline Measures to be taken immediately after exposure* & $\begin{array}{l}\text { Wash the area with soap and water } \\
\text { Wash the area with alcohol and iodine } \\
\text { Check patient and self HIV status } \\
\text { Squeeze for more bleeding } \\
\text { Seek PEP } \\
\text { Report to head person }\end{array}$ & $\begin{array}{l}89 \\
46 \\
78 \\
34 \\
21 \\
7\end{array}$ & $\begin{array}{l}41.0 \\
21.2 \\
35.9 \\
15.6 \\
9.7 \\
3.2\end{array}$ \\
\hline Knowledge about UP* & $\begin{array}{l}\text { Ever heard about UP } \\
\text { Types of protections } \\
\text { Hand washing before and after the procedure } \\
\text { Use of Protective barrier like a glove, gowns, mask } \\
\text { Correct handling of sharp materials } \\
\text { Disinfection and sterilization } \\
\text { Proper disposal of needles and waste }\end{array}$ & $\begin{array}{l}207 \\
190 \\
200 \\
143 \\
106 \\
97\end{array}$ & $\begin{array}{l}95.4 \\
87.5 \\
92.1 \\
65.9 \\
48.8 \\
44.7\end{array}$ \\
\hline
\end{tabular}

Note: *More than one answer is possible and percentages totals are based on respondents.

Abbreviations: OE, occupational exposure; UP, universal precaution.

\section{Knowledge About Post-Exposure Prophylaxis}

Almost all 210 (96.7\%) of respondents had information about PEP, of these, 158 (72.8\%) knew the availability of PEP in their facility, and the majority 149 (68.6\%) knew PEP as the combinations of three drugs. Seventy-eight (35.9\%) of the respondents mentioned that they know the regimen Tenofovir (TDF) + Lamivudine (3TC)+ Efavirenz (EFV) and/or Zidovudine (AZT)+ Lamivudine (3TC)+ Nevirapine (NVP). 53\% of the respondent mentioned that the period for initiation of PEP is within 24 hours after exposure, whereas $50.7 \%$ of the respondents mentioned that PEP should be initiated within 24-72 hours after exposure. One hundred and fourteen $(52.5 \%)$ of the respondents knew the recommended duration of treatments (4 weeks) (Table 3).

The overall score of knowledge questions revealed that $85(39.17 \%)$ of the respondents had moderate knowledge about PEP followed by 76 (35.02\%) who had poor knowledge and 56 (25.81\%) who had good knowledge (Figure 1).

Multinomial logistic regression analysis was done to see the association among variables by using the poor knowledge category as a baseline outcome. According to the multinomial logistic regression result, sex, qualification, and attitude status were found to have a significant association with knowledge regarding PEP. Those who have a good attitude had 2.25 and 2.89 times higher chance of having moderate and good knowledge ( $R R R=2.25,95 \%$ CI 1.09-4.67) and ( $R R R=2.89,95 \%$ CI 1.19-7.02) respectively. On the other hand, variables, like age, year of service, and taking training did not show significant association with knowledge about PEP (Table 4).

\section{Attitude Towards Post-Exposure Prophylaxis}

Most of the respondents 193 (88.9\%) believed that HIV would be acquired occupationally. The self-risk perception question showed that $173(79.7 \%)$ of the respondents believe that they have a risk of acquiring HIV infection occupationally. Of the total respondents, 83 (38.2\%) agree that initiation of PEP after 72 hours of exposure would be effective while 59 (27.2\%) disagree that staff should start PEP even if they are not willing to have an HIV test after occupational exposure (Table 5). 
Table 3 Knowledge About PEP Among Health Professionals in Health Centers in the Harari Region, Eastern Ethiopia, MarchApril 2019

\begin{tabular}{|c|c|c|c|}
\hline Variables & Response & Frequency & Percent \\
\hline \multirow[t]{2}{*}{ Heard about PEP } & Yes & 210 & 96.7 \\
\hline & No & 7 & 3.3 \\
\hline \multirow{2}{*}{$\begin{array}{l}\text { Know availability } \\
\text { in their facility }\end{array}$} & Yes & 158 & 72.8 \\
\hline & No & 59 & 27.2 \\
\hline \multirow[t]{4}{*}{$\begin{array}{l}\text { Number of drugs } \\
\text { to be combined* }\end{array}$} & $\begin{array}{l}\text { Three drug } \\
\text { combinations }\end{array}$ & 149 & 68.6 \\
\hline & $\begin{array}{l}\text { Two drug } \\
\text { combinations }\end{array}$ & 130 & 59.9 \\
\hline & One drug only & 66 & 30.4 \\
\hline & $\begin{array}{l}\text { More than three } \\
\text { combinations }\end{array}$ & 8 & 3.7 \\
\hline \multirow[t]{4}{*}{$\begin{array}{l}\text { Regimens they } \\
\text { know* }\end{array}$} & $\begin{array}{l}\mathrm{TDF}+3 \mathrm{TC}+\mathrm{EFZ} \\
\text { or } \mathrm{AZT}+3 \mathrm{TC}+\mathrm{NVP}\end{array}$ & 78 & 35.9 \\
\hline & TDF or AZT+EFV & 40 & 18.4 \\
\hline & AZT or NVP & 19 & 8.7 \\
\hline & Did not list any drug & 80 & 36.8 \\
\hline \multirow{4}{*}{$\begin{array}{l}\text { Optional period } \\
\text { of initiation* }\end{array}$} & Within 24 hrs. & 115 & 53 \\
\hline & Within $24-72$ hrs. & 110 & 50.7 \\
\hline & After 72 hrs. & 32 & 14.7 \\
\hline & Within one week & 8 & 3.7 \\
\hline \multirow{4}{*}{$\begin{array}{l}\text { Duration of } \\
\text { treatment }\end{array}$} & Iweek & 25 & 11.5 \\
\hline & 2weeks & 54 & 24.9 \\
\hline & 3weeks & 24 & II.I \\
\hline & 4weeks & 114 & 52.5 \\
\hline
\end{tabular}

Note: *More than one answer is possible and percentage totals are based on respondents.

The overall score of attitude questions results showed that the majority of respondents 147 (67.74\%) have a good attitude towards HIV PEP (Figure 2). Multivariate logistic regression analysis was done to see the association among variables.

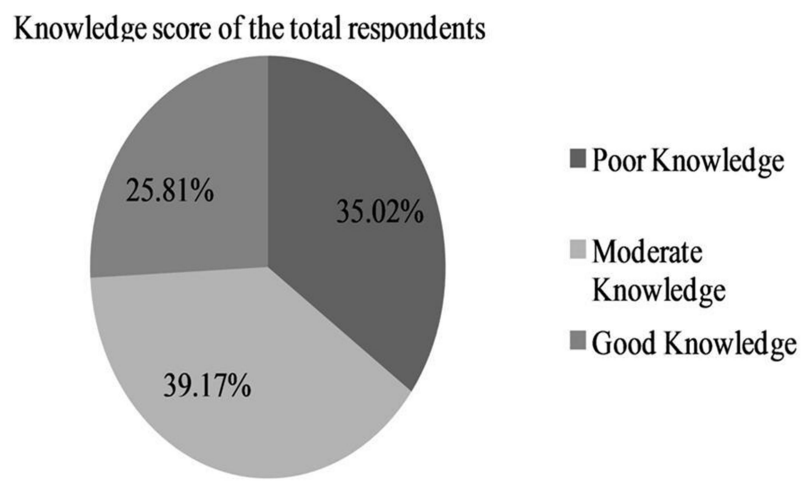

Figure I Overall knowledge score of health professionals in health centers in the Harari region, Eastern Ethiopia, March-April 2019.
According to the multivariate logistic regression result, knowledge status was found to have a significant association with the attitude towards PEP. The odd of PEP's good attitude were 2.29 and 2.32 times higher among those who had moderate and good knowledge when compared with those who had poor knowledge about PEP, respectively $(\mathrm{AOR}=02.29,95 \% \mathrm{CI} 1.07-4.91)$ and $(\mathrm{AOR}=2.32,95 \% \mathrm{CI}$ 1.03-5.38). On the other hand, variables, like age, sex and qualification did not show a significant association with an attitude towards PEP (Table 6).

\section{The Practice of Post-Exposure Prophylaxis}

From the total respondent, $128(59.0 \%)$ reported that they had been exposed to HIV risk factors while they are at the workplace. Of these, 71 (55.5\%) were exposed once. The two common types of encountered exposures by the respondents were needle stick injury $111(86.7 \%)$ followed by sharp cuts 52 (40.6\%) (Table 7). Of those who had exposure, $37(28.9 \%)$ of the respondents were exposed from source patient confirmed HIV positive, 42 (32.8\%) from unknown serostatus, and 49 (38.3\%) from HIV negative patients. Of 79 of the health professionals exposed to unknown and sero reactive patients, $54(68.4 \%)$ tried to get PEP service and of those 49 (90.7\%) started to use PEP. Out of 49 respondents who took PEP, 42 (85.7\%) had taken PEP once, and 5(10.2\%) reported to use PEP two times. The major reason for not starting PEP was the fear of its adverse effects $13(52 \%)$ (Table 8$)$.

The majority $143(65.8 \%)$ of respondents reported that they have had on/off service training on HIV PEP. The perceived reasons for OE to HIV/AIDS among respondents were negligence of HCWs 135 (62.2\%), followed by multiple procedures at the same time/heavy workloads 121 (55.7\%) (Table 9).

\section{Discussion}

The present study assessed KAP regarding PEP against HIV/AIDS. Almost all of the participants in the present study had information about the risk of OE, which is almost comparable with studies conducted in Woldia General Hospital, North-Eastern Ethiopia (95.28\%), ${ }^{9}$ Southwestern Nigeria $(93.3 \%)^{6}$ and Princess Marina Hospital Gaborone $(97.4 \%),{ }^{10}$ but higher than the study conducted in Asella Teaching Hospital, South-East Ethiopia (88.8\%). ${ }^{11}$ The higher result observed in the current study could be due to the time gap and difference in study participants, with the majority of the participant in the current survey had 
Table 4 Multinomial Logistic Regression Analysis of Knowledge and Associated Factors for Healthcare Professionals Towards PEP in Health Centers in the Harari Region, Eastern Ethiopia, March-April 2019

\begin{tabular}{|c|c|c|c|c|c|c|}
\hline \multicolumn{2}{|l|}{ Variables } & \multirow{2}{*}{\multicolumn{3}{|c|}{$\begin{array}{l}\text { Frequency and Percentage of } \\
\text { Knowledge Status }\end{array}$}} & \multirow[b]{3}{*}{ P-value } & \multirow[b]{3}{*}{$\operatorname{RRR}(95 \% \mathrm{Cl})$} \\
\hline \multicolumn{2}{|c|}{ Poor Knowledge (Baseline Outcome) } & & & & & \\
\hline \multicolumn{2}{|l|}{ Moderate Knowledge } & Poor & Moderate & Good & & \\
\hline \multirow[t]{5}{*}{ Age } & $20-25$ & $34(40.5)$ & $33(39.3)$ & $17(20.2)$ & & I \\
\hline & $26-30$ & $35(38.04)$ & $35(38.0)$ & $22(23.91)$ & 0.551 & $0.79(0.36-1.7 I)$ \\
\hline & $31-35$ & $3(18.8)$ & $7(43.8)$ & $6(37.5)$ & 0.524 & $1.71(0.33-8.92)$ \\
\hline & $35-40$ & I (14.3) & $4(57.1)$ & $2(28.6)$ & 0.75 & $1.53(0.11-21.14)$ \\
\hline & $>40$ & $I(10)$ & $5(50)$ & $4(40)$ & 0.315 & $3.4 I(0.31-37.5)$ \\
\hline \multirow[t]{2}{*}{ Sex } & Male & $31(28.7)$ & $51(47.2)$ & $26(24.07)$ & & 1 \\
\hline & Female & $43(42.6)$ & $33(32.7)$ & $25(24.8)$ & $0.038^{*}$ & $0.48(0.24-0.96)$ \\
\hline \multirow[t]{4}{*}{ Year of service } & $0-5$ & $48(39.3)$ & $52(42.6)$ & $22(18)$ & & I \\
\hline & $6-10$ & $21(36.2)$ & $17(29.3)$ & $20(34.5)$ & 0.122 & $0.47(0.18-1.23)$ \\
\hline & $11-15$ & $4(21.05)$ & $9(47.4)$ & $6(31.6)$ & 0.555 & $1.58(0.35-7.18)$ \\
\hline & $>15$ & I (I0) & $6(60)$ & $3(30)$ & 0.511 & $2.41(0.17-33.42)$ \\
\hline \multirow[t]{3}{*}{ Qualification } & Diploma & $44(44.9)$ & $4 \mid(4 \mid .8)$ & $13(13.3)$ & & I \\
\hline & BSc degree & $29(32.2)$ & $34(37.8)$ & $27(30.0)$ & 0.929 & $1.04(0.46-2.32)$ \\
\hline & MSc degree & I (4.8) & $9(42.9)$ & II (52.4) & 0.196 & $4.63(0.45-47.38)$ \\
\hline \multirow[t]{2}{*}{ Monthly income } & $<4000$ & $56(44.0)$ & 48 (37.8) & $23(18.1)$ & & 1 \\
\hline & $>4000$ & $18(21.9)$ & $36(43.9)$ & $28(34.2)$ & 0.137 & $2.04(0.79-5.23)$ \\
\hline \multirow[t]{2}{*}{ attitude } & Poor & $32(46.4)$ & $24(34.8)$ & $13(18.8)$ & & 1 \\
\hline & Good & $42(30)$ & $60(42.9)$ & $38(27.1)$ & $0.029^{*}$ & $2.25(1.09-4.67)$ \\
\hline \multirow[t]{2}{*}{ Ever taken training } & No & $27(36.5)$ & $29(39.2)$ & $18(24.3)$ & & \\
\hline & Yes & $47(34.8)$ & $55(40.7)$ & $33(24.4)$ & 0.807 & $1.09(0.54-2.23)$ \\
\hline \multicolumn{7}{|l|}{ Good knowledge } \\
\hline \multirow[t]{5}{*}{ Age } & $20-25$ & $34(40.5)$ & $33(39.3)$ & $17(20.2)$ & & 1 \\
\hline & $26-30$ & $35(38.04)$ & $35(38.0)$ & $22(23.91)$ & 0.49 & $0.7 \mid(0.27-1.87)$ \\
\hline & $31-35$ & $3(18.8)$ & $7(43.8)$ & $6(37.5)$ & 0.779 & $1.29(0.22-7.72)$ \\
\hline & $35-40$ & I (14.3) & $4(57.1)$ & $2(28.6)$ & 0.78 & $1.57(0.07-36.76)$ \\
\hline & $>40$ & $I(10)$ & $5(50)$ & $4(40)$ & 0.394 & $3.05(0.23-39.78)$ \\
\hline \multirow[t]{2}{*}{ Sex } & Male & 31 (28.7) & $51(47.2)$ & $26(24.07)$ & & I \\
\hline & Female & $43(42.6)$ & $33(32.7)$ & $25(24.8)$ & 0.896 & $0.94(0.4 I-2.19)$ \\
\hline \multirow[t]{4}{*}{ Year of service } & $0-5$ & $48(39.3)$ & $52(42.6)$ & $22(18)$ & & 1 \\
\hline & $6-10$ & $21(36.2)$ & $17(29.3)$ & $20(34.5)$ & 0.462 & $1.48(0.52-4.24)$ \\
\hline & $11-15$ & $4(21.05)$ & $9(47.4)$ & $6(31.6)$ & 0.113 & $4.00(0.7 I-22.23)$ \\
\hline & $>15$ & I (I0) & $6(60)$ & $3(30)$ & 0.386 & $3.61(0.19-66.09)$ \\
\hline \multirow[t]{3}{*}{ Qualification } & Diploma & $44(44.9)$ & $4 \mid(4 I .8)$ & $13(13.3)$ & & 1 \\
\hline & BSc degree & $29(32.2)$ & $34(37.8)$ & $27(30.0)$ & $0.029 *$ & $2.93(1.12-7.69)$ \\
\hline & MSc degree & I (4.8) & $9(42.9)$ & II (52.4) & $0.002 *$ & $40.32(3.68-44 \mid .28)$ \\
\hline \multirow[t]{2}{*}{ Monthly income } & $<4000$ & $56(44.0)$ & $48(37.8)$ & $23(18.1)$ & & I \\
\hline & $>4000$ & $18(21.9)$ & $36(43.9)$ & $28(34.2)$ & 0.831 & $1.11(0.40-3.12)$ \\
\hline \multirow[t]{2}{*}{ Attitude status } & Poor & $32(46.4)$ & $24(34.8)$ & $13(18.8)$ & & 1 \\
\hline & Good & $42(30)$ & $60(42.9)$ & $38(27.1)$ & $0.019 *$ & $2.89(1.19-7.02)$ \\
\hline \multirow[t]{2}{*}{ Ever taken training on PEP } & No & $27(36.5)$ & $29(39.2)$ & $18(24.3)$ & & 1 \\
\hline & Yes & $47(34.8)$ & $55(40.7)$ & $33(24.4)$ & 0.913 & $0.95(0.40-2.22)$ \\
\hline
\end{tabular}

Note: *Significant association. 
Table 5 Attitudes of Health Professionals Towards PEP, in Health Centers of Harari Region, Eastern Ethiopia, March-April 2019

\begin{tabular}{|l|l|l|l|}
\hline Questions & Response & Frequency & Percent \\
\hline HIV would be acquired & Agree & 193 & 88.9 \\
occupationally & Disagree & 20 & 9.2 \\
& Neutral & 4 & 1.8 \\
You are one of those, at risk & Agree & 173 & 79.7 \\
of acquiring HIV & Disagree & 33 & 15.2 \\
occupationally & Neutral & 11 & 5.1 \\
Universal precaution & Agree & 165 & 76.0 \\
methods are protective & Disagree & 37 & 17.1 \\
from occupational exposure & Neutral & 15 & 6.9 \\
to HIVIAIDS & & & \\
Occupational exposure is & Agree & 136 & 62.6 \\
avoidable by universal & Disagree & 52 & 23.9 \\
precaution and PEP. & Neutral & 29 & 13.4 \\
ARV drugs are effective & Agree & 125 & 57.3 \\
after occupational exposure & Disagree & 75 & 34.6 \\
to prevent HIV/AIDS. & Neutral & 17 & 7.8 \\
PEP initiation after 72 hours & Agree & 83 & 38.2 \\
of exposure would be & Disagree & 125 & 57.6 \\
effective & Neutral & 9 & 4.2 \\
Staffs should start PEP even & Agree & 127 & 58.5 \\
if they are not willing to & Disagree & 59 & 27.2 \\
have an HIV test after & Neutral & 31 & 14.3 \\
occupational exposure & & & \\
\hline
\end{tabular}

a Diploma. Regarding types of exposure they knew, the majority identified the high-risk exposure of sharp cut and needle stick injury, which is similar to a finding reported in a study conducted in Nigeria $(81.7 \%$ and $88.5 \%$ identified mucocutaneous exposure and percutaneous exposures as high risk, respectively). ${ }^{12}$

In the current study, less than half of the respondents had poor knowledge, which is slightly higher than a study conducted among HCWs in public health institutions in

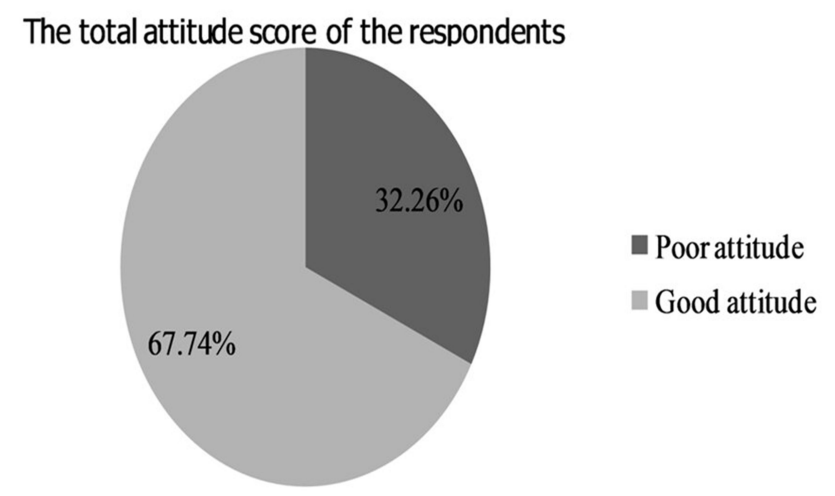

Figure 2 Overall attitude score toward PEP against HIV among health professionals in health centers in the Harari region, Eastern Ethiopia, March-April 2019.
Debre Markos town (36.1\%), ${ }^{7}$ a study conducted in Gondor, northwest Ethiopia $(36.9 \%)^{13}$ and a study conducted in Hiwot Fana Specialized University Hospital in Harar (17\%), ${ }^{14}$ but much lower than the study conducted in Nigeria $(57 \%)^{6}$ and a study conducted at Jigme Dorji Wangchuck National Referral Hospital, Bhutan (80.1\%). ${ }^{15}$ This could be due to the difference in the knowledge assessment like the availability of PEP service and training in this survey and also a difference in the study setting and the difference in health professionals involved in the study.

Self-risk perception question in the present study showed that the majority of the respondents believe that they have a risk of acquiring HIV infection occupationally which is in line with a study conducted in India where $89 \%$ of respondents considered themselves to be at risk of HIV acquisition at their workplace. ${ }^{17}$ Almost one-fourth of the respondents did not believe that OE to HIV/AIDS is avoidable which is much higher than a study in China which showed that $10 \%$ of respondent believes OE was unavoidable. ${ }^{18}$ More than half of respondents accept that ARV drugs are effective after OE; however, this is lower than a similar study conducted in Lagos University Teaching Hospital in Nigeria (73\%). ${ }^{19}$ This huge gap could be due to differences in knowledge and training they had since in the present study, one-third of the professionals did not attain any training. This study found that the majority of the respondents had a favorable attitude towards PEP for HIV which is comparable with the study conducted among HCW in Debre Markos town (69.8\%). ${ }^{7}$

\section{Practice Towards PEP}

In this study, more than half of the respondents reported that they have been exposed to HIV risk conditions while they are at the workplace. This finding is higher than the study done in Botswana (53.7\%), ${ }^{10}$ Gondar $(33.8 \%),{ }^{13}$ Gimbi town $(50 \%)^{16}$ and Cameroon $(50.8 \%) .{ }^{20}$ Whereas, it is much lower than a study done in Ghana $(83.2 \%){ }^{21}$ This could be because of the difference in the study area and population and the difference in the workload.

Regarding immediate measures taken after exposure, half of the respondents in the current study reported that they washed the exposed area with water and soap and one-fourth washed the exposed area with alcohol and iodine, whereas a study conducted in Debre Markos revealed that $68.6 \%$ of respondents washed the wound with soap and water and $14.9 \%$ squeezed and washed with alcohol. ${ }^{7}$

In the present study, almost one-tenth of the study participants did not use PEP, which is lower when 
Table 6 Multiple Logistic Regression Analysis of Attitude and Associated Factors for Healthcare Professionals Towards PEP in Health Centers in the Harari Region, Eastern Ethiopia, March-April 2019

\begin{tabular}{|c|c|c|c|c|c|}
\hline \multicolumn{2}{|l|}{ Variables } & \multicolumn{2}{|c|}{ Attitude Status } & \multirow[b]{2}{*}{ P-value } & \multirow[b]{2}{*}{ AOR(95\% Cl) } \\
\hline & & Good & Poor & & \\
\hline Age & $\begin{array}{l}20-25 \\
26-30 \\
31-35 \\
35-40 \\
>40\end{array}$ & $\begin{array}{l}48(59.2) \\
71(75.5) \\
\text { II (64.7) } \\
6(85.7) \\
7(58.3)\end{array}$ & $\begin{array}{l}33(40.7) \\
23(24.5) \\
6(35.3) \\
1(14.3) \\
5(41.7)\end{array}$ & $\begin{array}{l}0.07 \\
0.53 \\
0.97 \\
0.248\end{array}$ & $\begin{array}{l}\text { I } \\
2.01(0.94-4.28) \\
0.64(0.16-2.57) \\
0.95(0.08-11.20) \\
0.37(0.07-1.99)\end{array}$ \\
\hline Sex & $\begin{array}{l}\text { Male } \\
\text { Female }\end{array}$ & $\begin{array}{l}76(71.0) \\
67(64.2)\end{array}$ & $\begin{array}{l}31(28.9) \\
37(35.5)\end{array}$ & 0.303 & $\begin{array}{l}\text { I } \\
0.69(0.35-1.38)\end{array}$ \\
\hline Year of service & $\begin{array}{l}0-5 \\
6-10 \\
11-15 \\
>15\end{array}$ & $\begin{array}{l}77(64.7) \\
41(68.3) \\
15(75) \\
10(83.3)\end{array}$ & $\begin{array}{l}42(35.3) \\
19(31.7) \\
5(25) \\
2(16.7)\end{array}$ & $\begin{array}{l}0.553 \\
0.71 \\
0.337\end{array}$ & $\begin{array}{l}\text { I } \\
\text { I.32 }(0.53-3.27) \\
\text { I.3I }(0.3 \mathrm{I}-5.45) \\
2.73(0.35-21.39)\end{array}$ \\
\hline Qualification & $\begin{array}{l}\text { Diploma } \\
\text { BSc degree } \\
\text { MSc degree }\end{array}$ & $\begin{array}{l}67(68.3) \\
58(63.0) \\
18(81.8)\end{array}$ & $\begin{array}{l}31(31.6) \\
34(36.9) \\
4(18.2)\end{array}$ & $\begin{array}{l}0.06 \\
0.252\end{array}$ & $\begin{array}{l}\text { I } \\
0.45(0.19-1.03) \\
3.97(0.37-42.16)\end{array}$ \\
\hline Monthly income & $\begin{array}{l}<4000 \\
>4000\end{array}$ & $\begin{array}{l}78(62.4) \\
65(74.7)\end{array}$ & $\begin{array}{l}47(37.6) \\
22(25.3)\end{array}$ & 0.227 & $\begin{array}{l}\text { I } \\
\text { I.7I (0.7I-4.09) }\end{array}$ \\
\hline Knowledge status & $\begin{array}{l}\text { Poor } \\
\text { Moderate } \\
\text { Good }\end{array}$ & $\begin{array}{l}42(56.7) \\
60(73.2) \\
38(74.5)\end{array}$ & $\begin{array}{l}32(43.2) \\
22(26.8) \\
13(25.5)\end{array}$ & $\begin{array}{l}0.033^{*} \\
0.049 *\end{array}$ & $\begin{array}{l}\text { I } \\
2.29(1.07-4.91) \\
2.32(1.03-5.38)\end{array}$ \\
\hline
\end{tabular}

Note: *Significant association.

Table 7 Exposure and Measures Taken by the Health Professionals After Exposure in Health Centers in the Harari Region, Eastern Ethiopia, March-April 2019

\begin{tabular}{|c|c|c|c|}
\hline Questions & Response & Frequency & Percent \\
\hline \multirow[t]{2}{*}{ Ever exposed while at work } & Yes & 128 & 59.0 \\
\hline & No & 89 & 41.0 \\
\hline \multirow[t]{3}{*}{ Frequency of encountered exposure } & Once & 71 & 55.5 \\
\hline & Twice & 30 & 23.4 \\
\hline & Three and more times & 27 & 21.1 \\
\hline \multirow[t]{4}{*}{ Type encountered exposures* } & Needlestick & 111 & 86.7 \\
\hline & Sharp cut & 52 & 40.6 \\
\hline & Mucosal contact & 44 & 34.4 \\
\hline & Others(splash of body fluid) & 12 & 9.4 \\
\hline \multirow[t]{5}{*}{ Immediate measures after exposures* } & Washed with soap and water & 72 & 56.2 \\
\hline & Washed with alcohol and iodine & 32 & 25.0 \\
\hline & Check patient and self HIV status & 98 & 76.5 \\
\hline & Applied pressure to stop bleeding & 18 & 14.0 \\
\hline & Reported the occurrence of injury & 15 & 11.7 \\
\hline
\end{tabular}

Note: *More than one answer is possible and percentage totals are based on respondents.

compared with a study conducted in Botswana $(74.8 \%),{ }^{10}$ a study in Bhutan $(97.9 \%)^{15}$ and a study from Debre Markos town $(56.7 \%) .^{7}$ This might be due to differences in the number of those individuals who were exposed and in general due to the difference in the number of the study participants and the difference in the percentile calculation 
Table 8 Distribution of Serostatus of Source Patient and Practice of HCWs Towards PEP, Among Health Centers in Harari Region, Eastern Ethiopia, March 2019

\begin{tabular}{|c|c|c|c|}
\hline Variables & Category & Frequency & Percent \\
\hline \multirow[t]{3}{*}{ Sero-status of the source patient } & Positive & 37 & 28.9 \\
\hline & Negative & 49 & 38.3 \\
\hline & Unknown & 42 & 32.8 \\
\hline \multirow[t]{2}{*}{ Tried to get PEP service } & YES & 54 & 68.4 \\
\hline & NO & 25 & 31.6 \\
\hline \multirow[t]{2}{*}{ Started to use PEP } & YES & 49 & 90.7 \\
\hline & NO & 5 & 9.3 \\
\hline \multirow[t]{4}{*}{ Duration of starting PEP after exposure } & $=<$ One hour & 5 & 10.2 \\
\hline & $6-24$ hours & 26 & 53.1 \\
\hline & 24-72 hours & 18 & 36.7 \\
\hline & After 72 hours & 0 & 0 \\
\hline \multirow[t]{2}{*}{ Completed treatment according to prescription } & Yes & 44 & 89.8 \\
\hline & No & 5 & 10.2 \\
\hline \multirow[t]{2}{*}{ Check their status after treatment } & Yes & 32 & 65.3 \\
\hline & No & 17 & 34.7 \\
\hline \multirow[t]{4}{*}{ Frequency of taking PEP } & Once & 42 & 85.7 \\
\hline & Twice & 5 & 10.2 \\
\hline & Three times & 2 & 4.1 \\
\hline & More than three times & 0 & 0 \\
\hline \multirow[t]{4}{*}{ The reason not to start PEP } & Because of adverse effects & 13 & 52 \\
\hline & Lack of information on the existence of service & 9 & 36 \\
\hline & Because of social stigma & 2 & 8 \\
\hline & Others & 1 & 4 \\
\hline
\end{tabular}

Table 9 Distribution of Previous Training on PEP and Perceived Reason for Occupational Exposure, Among Health Professionals in Health Centers in the Harari Region, Eastern Ethiopia, March-April 2019

\begin{tabular}{|l|l|l|l|}
\hline Variables & Category & Frequency & Percent \\
\hline Any on/off service training on PEP of HIV & Yes & 143 & 65.9 \\
& No & 74 & 34.1 \\
\hline What do you think is the reason for the occupational exposure* & Negligence of health professionals & 135 & 62.2 \\
& Multiple procedures at the same time/heavy workloads & 121 & 83 \\
& Lack of knowledge on the risk & 97 & 38.2 \\
& Recapping of needle & 44.7 & 105 \\
& Uncooperative patient & 75 & 34.6 \\
\hline
\end{tabular}

Note: *More than one answer is possible and percentage totals are based on respondents.

of this result being from the exposed participant who tried to get the service.

In this study, the major reasons for not taking PEP were fear of its adverse effects and lack of information about the existence of service. A similar study in Debre Markos Ethiopia revealed that $52.6 \%$ did not take PEP because the source patient was HIV negative and 31.5\% because of negligence and unaware of PEP. ${ }^{7}$ The study in Bhutan however showed that the major reasons were the absence of PEP service (30.2\%) and lack of support to report incidents $(22.6 \%) .{ }^{15}$ Whereas a study from Jimma reported that $33.8 \%$ of the respondents were unaware of 
the existence of PEP service and protocol, 23.2\% had a lack of understanding on the value of reporting exposures, and $32.2 \%$ had a fear stigma and discrimination. ${ }^{22}$ Reasons for the observed differences of findings between different research results could be due to the differences in the level of awareness between the different population, economic status, qualification of the study population and time difference of the studies, sample size differences, and study setting difference (most of the literature compared with the current study were conducted in a hospital).

According to the present study, sex, qualification, and attitude status were found to have a significant association with knowledge regarding PEP. On the other hand, the study in Debre Markos shows a strong association of profession and attitude with knowledge, ${ }^{7}$ the study in Asella shows an association of young age, female gender, low educational status, low work experience with knowledge regarding PEP, ${ }^{11}$ the study in Kenya shows the association of gender, level of education and job cadre with knowledge ${ }^{8}$ whereas the study in Gimbi, ${ }^{16}$ Jimma zone ${ }^{22}$ and Buhta ${ }^{15}$ has shown no association between knowledge and other variables (attitude).

\section{Conclusion}

The majority of health professionals have heard about OC, UP, and PEP and have a good attitude towards PEP. However, the majority had moderate and poor knowledge and also poor practice regarding PEP, as is evidenced by unnecessary measures taken and under and/or improper utilization of PEP. In general, the findings of this study revealed there is a gap in the KAP of health professionals towards PEP for HIV. The information gap present with the professional can be enhanced by training the professionals more about PEP and awareness programs and a proper guideline should be implemented for better utilization of the PEP. Besides, more efforts should be done by the institutions as well as the health professionals to reduce the risk of exposure while rendering service.

\section{Abbreviations}

AIDS, acquired immune deficiency syndrome; ARV, anti retroviral; HCWs, healthcare workers; HCs, health centers; HIV, human immunodeficiency virus; KAP, knowledge, attitude and practice; OE, occupational exposure; PEP, post-exposure prophylaxis; UP, universal precaution.

\section{Data Sharing Statement}

The datasets used and/or analyzed during the current study are available from the corresponding author on reasonable request.

\section{Ethics Approval and Consent to Participate}

A letter of clearance was obtained from Haramaya University, College of Medical and Health Science, School of Pharmacy, and submitted to the Harari Health Biro to obtain permission to conduct the research. All data obtained in the course of the study were kept confidential and used solely for the study. Moreover, the questioner was given to the health professionals based on informed consent and their will. Further, they were able to choose which questions to answer. The respondents were informed that the results of the study would be analyzed at the group level; that no individual would be able to be identified; and that data would be used for research purposes only.

\section{Consent for Publication}

Not applicable

\section{Acknowledgments}

The authors are thankful to all individuals who were involved in the research.

\section{Author Contributions}

All authors contributed to data analysis, drafting or revising the article, have agreed on the journal to which the article will be submitted, gave final approval of the version to be published, and agree to be accountable for all aspects of the work.

\section{Funding}

This study received no support from a funding agency.

\section{Disclosure}

The authors declare that they have no conflicts of interest for this work.

\section{References}

1. UNAIDS.Joint UN Program on HIV/AIDS, report on global HIV epidemics. 2012. Available from: https://www.unaids.org/sites/default/files/ media_asset/AIDSbythenumbers2012en. Accessed December 29, 2020.

2. Merkelz AE, Okulic JF, Bartlet J. Post-exposure HIV prophylaxis in physician and medical personnel. Medscape. 2019. Available from: https://emedicine.medscape.com/article/1991375-overview. Accessed December 29, 2020.

3. Panilion AL, Cardo DM, Grohskopf LA, Heneine W, Ross CS Updated US Public Health Service Guidelines. For the management of occupational exposure to HIV and recommendations for PEP. Available from: https://www.cdc.gov/mmwr/preview/mmwrhtml/ rr5409a1.htm. Accessed December 29, 2020.

4. US Department of Health and Human Services. Post exposure prophylaxis. 2011: 12-124 Available from: http://www.aids.gov/hiv.aidsbasics/prevention/postexposureproph. Accessed December 29, 2020. 
5. CDC. Occupational HIV transmission and prevention among health care worker workers: center for disease control: HIV in health care setting. 2016; 24-26. Available from: www.cdc.gov/mmwr. Accessed December 29, 2020.

6. Adebimpe WO. Knowledge and Practice of Health Care Workers Towards Post-Exposure Prophylaxis in the Era of Low and Stable HIV Prevalence in Southwestern Nigeria. Bulletin of Faculty of Pharmacy, Cairo University; 2018:104-108.

7. Biyadgie A, Tamir Y, Alem G. Knowledge, attitude, practice, and associated factors towards post-exposure prophylaxis to HIV infection among health care professionals in Debre Markos town public health institutions, Northwest Ethiopia. Clin Pract. 2017;14(6): 385-395.

8. Eumice W. Factors contributing for the uptake and compliance with HIV PEP at Kenyatta National Hospital Nairobi Kenya. 2011;4 (3):231-435.

9. Erukeya H, Baye F, Awole S, Abebe MS. Assessment of knowledge, attitude \& practice of health professionals towards post exposure prophylaxis of HIV/AIDS in Woldia General Hospital, Woldia, North-Eastern Ethiopia. Int J Biosci Healthcare Technol Manage. 2018;8(1):1-10.

10. Bareki P, Tenego T. Assessment of knowledge attitudes and practice of HIV post-exposure prophylaxis among the doctors and nurses in Princess Marina Hospital. Pan Afr Med J. 2018;30:233.

11. Birhanu A, Demessie A, Fantahun A, Gebrekirstos K. Awareness of post-exposure prophylaxis of HIV among health care personnel in Asella Teaching Hospital, Asella Town, South-East Ethiopia. Clin Med Res. 2014;4(3):69-74.

12. Agaba PA, Agaba EI, Ocheke AN, Daniyam CA, Akanbi MO, Okeke EN. Awareness and knowledge of HIV post exposure prophylaxis among nigerian family physicians. Niger Med J. 2012;53 (3):15560. doi:10.4103/0300-1652.104386

13. Mathewos B, Birhan W, Kinfe S, et al. Assessment of knowledge, attitude and practice towards post-exposure prophylaxis for HIV among health care workers in Gondar, North West Ethiopia. BMC Public Health. 2013;13(508). doi:10.1186/1471-2458-13-508

14. Eticha EM, Gemeda AB. Knowledge, attitude, and practice of postexposure prophylaxis against HIV infection among Healthcare workers in Hiwot Fana Specialized University Hospital, Eastern Ethiopia. AIDS Res Treat. 2019;2019:7947086. doi:10.1155/2019/7947086
15. Tshering K, Wangchuk K, Letho Z. Assessment of knowledge, attitude, and practice of post-exposure prophylaxis for HIV among nurses at Jigme Dorji Wanghuck National Referral Hospital, Bhutan. PLoS One. 2020;15(8):e0238069. doi:10.1371/journal.pone. 0238069

16. Tesfaye G, Gebeyehu H, Likisa J. Knowledge, attitude and practice towards HIV post-exposure prophylaxis of health professionals of Gimbi town in Ethiopia: a cross-sectional study. Int J Res Med Sci. 2014;2(2):468-471. doi:10.5455/2320-6012.ijrms20140517

17. Dulcie CA, Mohamed TS, Meenakshi B, Ezhil RJ. Assessment of knowledge about post-exposure prophylaxis of HIV among medical, nursing, and paramedical students in hospital and laboratory practice. Int J Basic Clin Pharmacol. 2017;6(10):2408-2413. doi:10.18203/ 2319-2003.ijbcp20174368

18. Lin CH, Li L, Wu Z, Wu S, Jia M. Occupational exposure To HIV among health care providers: a qualitative study in Yunnan, China. Int Assoc Phys AIDS Care. 2008;7(1):35-41. doi:10.1177/154510 9707302089

19. Ajibola S, Akinbami A, Elikwu C, Odesanya M, Uche E. Knowledge, attitude, and practices of HIV post-exposure prophylaxis amongst health workers in Lagos University Teaching Hospital. Pan Afr Med J. 2018;19:172.

20. Ngwa CH, Ngoh EA, Cumber SN. Assessment of the knowledge, attitude, and practice of health care workers in Fako Division on post-exposure prophylaxis to bloodborne viruses: a hospital-based cross-sectional study. Pan Afr Med J. 2018;31:108. doi:10.11604/ pamj.2018.31.108.15658

21. Babanawo F. Assessment of Knowledge and Use of HIV PostExposure Prophylaxis and Healthcare Workers' Risk to Occupational Exposure in New Juabeng Municipality, University of Ghana, Legon. University of Ghana; 2016:23-84. http://ugspace.ug. edu.gh. Accessed December 29, 2020.

22. Bosena T, Hailu C. Assessment of HIV post-exposure prophylaxis use among health workers of governmental health institutions in Jimma zone, Oromiya region, southwest Ethiopia. Ethiop J Health Sci. 2014;20(1):53-64.
HIV/AIDS - Research and Palliative Care

\section{Publish your work in this journal}

HIV/AIDS - Research and Palliative Care is an international, peerreviewed open-access journal focusing on advances in research in HIV, its clinical progression and management options including antiviral treatment, palliative care and public healthcare policies to

\section{Dovepress}

control viral spread. The manuscript management system is completely online and includes a very quick and fair peer-review system, which is all easy to use. Visit http://www.dovepress.com/testimonials.php to read real quotes from published authors. 